\title{
GOOGLE CLASSROOM COMO FERRAMENTA EDUCACIONAL NA PROPOSTA DE ENSINO HÍBRIDO NO PCNA
}

Lukas Ribeiro Moura de Sousa - lukas.sousa@itec.ufpa.br

Sandro Mateus Gonçalves Monteiro - sandro.monteiro@itec.ufpa.br

Adrian Daví de Lima Gonçalves - adrian.gonçalves@itec.ufpa.br

Paulo Henrique de Lima Souza - paulo.lima.sousa@itec.ufpa.br

Alexandre Guimarães Rodrigues-alexgr@ufpa.br

ShirleyCristina Cabral Nascimento-sccn@ufpa.br

Universidade Federal do Pará, Instituto de Tecnologia

Rua Augusto Corrêa, $n^{o}$ 01, Cidade Universitária Prof. José da Silveira Netto

66.075-110-Belém - Pará

Resumo: É notória a deficiência de conhecimentos apresentada pelos ingressantes dos cursos de engenharia oriundos da escola pública. Uma consequência desse problema se reflete nos índices de retenção e reprovação, uma vez que essa deficiência não permite ao aluno acompanhar o curso e concluí-lo no tempo mínimo. Na tentativa de minimizar essas consequências, são de extrema importância iniciativas e estratégias tais como o Programa de Cursos de Nivelamento da Aprendizagem (PCNA) da Universidade Federal do Pará (UFPA), proposta voltada a reduzir os índices de reprovação nos cursos de engenharia por meio da oferta de cursos de nivelamento. Utilizando uma abordagem quantitativa baseada no método Survey interseccional, o presente artigo busca analisar o impacto e a efetividade do uso da plataforma Google Classroom como ferramenta educacional para os alunos de um curso de nivelamento presencial com o apoio de recursos virtuais de ensino e aprendizado. A adesão à metodologia, a acessibilidade, a disponibilidade dos recursos ofertados e o estímulo ao estudo autônomo apresentaram resultados positivos após a realização do curso. Com isso, espera-se estimular o uso de tais ferramentas por parte das instituições educacionais, principalmente no atual contexto, em que o ensino remoto tornou-se necessário.

Palavras-chave: Ensino híbrido. Sala de aula invertida. Google Classroom. PCNA.

\section{INTRODUÇÃO}

Ao admitir e incentivar a democratização do ensino superior, as instituições precisam perceber que têm acesso a ele alunos com diferenças de desempenho no ensino médio (BARDAGI e HUTZ, 2005). A defasagem educacional dos ingressantes da educação superior manifesta-se desde o ensino médio, tanto por dificuldades inerentes do próprio aluno, quanto por dificuldades institucionais da rede pública de ensino. Tais obstáculos são motivadores da evasão universitária, onde no Brasil, em 2017, observou-se uma taxa de 25,9\% de evasão ao longo dos cursos presenciais de ensino superior do país (SEMESP, 2019). O Instituto de Tecnologia (ITEC) da Universidade Federal do Pará (UFPA) enfrenta este problema com a ajuda do Programa de Cursos de Nivelamento de Aprendizagem (PCNA), no qual, durante um curso de três semanas, os alunos passam por um nivelamento de conteúdos pré-requisitos às disciplinas iniciais dos cursos de graduação. 
Até o ano de 2019, o curso de nivelamento era ministrado integralmente nos turnos matutino e vespertino, o que provocava um acentuado índice de evasão do nivelamento. Frente a essa situação, em 2020, o PCNA viu nas tecnologias educacionais e no ensino semipresencial uma oportunidade de atenuar o referido problema. $\mathrm{O}$ ensino híbrido foi adotado, este, uma metodologia ativa de ensino que repensa o papel do professor, do aluno e do espaço educacional, utilizando recursos tecnológicos que, segundo Moran (2013), instigam as instituições a sair do ensino tradicional, tirando do professor e colocando no aluno no centro do processo de ensino e aprendizagem com momentos presenciais e a distância.

O curso de nivelamento, agora somente no turno matutino, seguiu um modelo de ensino híbrido, que promove uma mistura entre o ensino presencial e propostas de ensino online, integrando a educação à tecnologia. Como proposta de ensino online, utilizou-se a sala de aula invertida, metodologia que busca inverter o modelo educacional clássico, levando mais autonomia e protagonismo para os estudantes. Essa estratégia possibilitou o andamento do curso sem grandes disrupções ao conteúdo programático já existente. $\mathrm{O}$ ambiente virtual de ensino adotado para esse primeiro contato foi o Google Classroom (Google Sala de Aula), pois além de ser gratuito, proporciona uma variedade de ferramentas que motivam os alunos a serem proativos e autônomos nos estudos (MORAN, 2013).

Desta forma, o presente artigo tem por objetivo avaliar a percepção do aluno cursista PCNA sobre esta nova forma de ensino, a efetividade das ferramentas educacionais utilizadas, o nível de incentivo ao estudo autônomo ocasionado por esse novo método e identificar as dificuldades que os alunos encontraram no ambiente virtual de ensino.

\section{REVISÃO BIBLIOGRÁFICA}

\subsection{Ensino híbrido}

O palco central de desenvolvimento da educação, a sala de aula, vem há muito tempo sendo tomado por aparatos tecnológicos que objetivam potencializar o ensino. Nesse contexto surge o Ensino Híbrido com a proposta se aproveitar, ao máximo, essa configuração de interação educacional. A expressão "híbrido" significa "misturar" ou "mesclar" e, segundo Moran (2015, p.27), "a educação sempre foi misturada e híbrida passo de combinar vários espaços, tempos, atividades, metodologias e público". Assim, definir-se o ensino híbrido:

(...) como um programa de educação formal no qual um aluno aprende, pelo menos em parte, por meio do ensino online, com algum elemento de controle do estudante sobre o tempo, lugar, modo e/ou ritmo do estudo, e pelo menos em parte em uma localidade física supervisionada, fora de sua residência (CHRISTENSEN; HORN; STAKER, 2013, p. 7).

Em um espaço tradicional de sala de aula, o professor e os alunos, ao se relacionarem com as ferramentas e recursos do universo virtual, criam um ambiente capaz de desenvolver no aluno capacidades críticas antes não nutridas em métodos tradicionais de ensino. Neste intervalo de interação, destacam-se dois caminhos: o sustentado e o disruptivo. O primeiro caminho propõe mudanças progressivas e mantêm o modelo curricular predominante, mas prioriza o envolvimento maior do aluno por meio de metodologias ativas. $\mathrm{O}$ segundo possui mudanças mais profundas e inovadoras que redesenham o projeto, os espaços físicos, metodologias e que visa grande parte de seu tempo em ensino online.

O ensino híbrido está emergindo como uma inovação sustentada em relação à sala de aula tradicional. Neste modelo procura-se "o melhor dos dois mundos", ou seja, as vantagens da educação online e da sala de aula tradicional (CHRISTENSEN; HORN; STAKER, 2013, p. 3). As citadas vantagens da educação online vão desde materiais disponibilizados em plataformas na nuvem até monitorias e tutorias em tempo real. 
"Os desafios para formar hoje o engenheiro do amanhã"

\subsection{Sala de aula invertida}

A sala de aula invertida busca transformar alunos de ouvintes passivos para personagens ativos em seu aprendizado. Esse método se sustenta na inversão da sala de aula tradicional e do ambiente de aprendizado fora dela, onde o contato primário do aluno com o assunto é feito online, geralmente na sua própria casa. Assim, ele tem controle sobre tempo e ritmo de aprendizado (CHRISTENSEN; HORN; STAKER, 2013), além da disponibilidade de ferramentas tecnológicas (videoaulas, eBooks, exercícios online, etc.). Logo, o professor assume uma posição condutora do conhecimento, uma vez que o tempo em sala de aula pode ser usado para práticas que consolidam o conhecimento como aulas complementares, debates e resolução de exercícios, interligando o novo e o prévio conhecimento. Nessa dinâmica, Moreira (2000) destaca que a nova informação adquire significados e a informação prévia fica mais rica e estável e, nesse processo, o aluno constrói seu próprio conhecimento.

\subsection{Programa de Cursos de Nivelamento da Aprendizagem - PCNA}

O fenômeno da evasão hoje, é uma questão não só educacional, mas também econômica e política, reduzi-la produziria um impacto positivo nas trajetórias individuais dos alunos, além de um impacto financeiro e social positivo para as instituições de ensino superior (BARDAGI; HUTZ, 2005). Em vista disso, nasce, em 2011, na Universidade Federal do Pará (UFPA), o Programa de Cursos de Nivelamento da Aprendizagem (PCNA), com o intuito de fortalecer a formação em ciências elementares dos ingressantes dos cursos de engenharia. $\mathrm{O}$ programa do Instituto de Tecnologia (ITEC), mantido pela Superintendência de Assistência Estudantil da UFPA (SAEST), funciona por meio de monitorias e plantões de dúvidas de Cálculo I e II, Química Teórica e Experimental, Física I e II e Tecnologia Elementar, durante o semestre letivo. Outro pilar do PCNA é o curso de nivelamento que ocorre no período intervalar anterior ao início do primeiro semestre dos calouros, tendo duração de três semanas, onde são aplicadas aulas presenciais de Matemática Elementar, Física Elementar, Química Elementar e Tecnologia Elementar em turmas de, em média, 40-45 alunos, divididas por cursos de engenharia. Ao final do curso, dependendo da assiduidade e rendimento do aluno, é emitido um certificado de carga horária complementar. Ainda durante o período de nivelamento, plantões de dúvidas e aulas experimentais de Química ocorrem em paralelo. Todas as atividades citadas anteriormente são realizadas por uma equipe de monitoresbolsistas e monitores-voluntários orientados pelos professores coordenadores do projeto.

\subsection{Ambientes virtuais de ensino}

Os rápidos avanços tecnológicos trouxeram à área da educação ferramentas poderosas para seu desenvolvimento. Segundo Witt (2015), estes aparatos "incentivam professores e pesquisadores a desenvolverem ambientes virtuais que cultivem nos alunos e nos professores as habilidades de aprender e inovar". Neste novo âmbito de aprendizagem se destacam algumas plataformas com materiais e didática pré-estabelecidos como a Khan Academy, e outras que dão liberdades criativa e metodológica para seus usuários como o Moodle (Ambiente de Aprendizado Objeto-Orientado Dinâmico Modular) e o Google Classroom.

A eficácia desses ambientes de ensino pode ser observada no Projeto Newton, iniciativa de ensino de Cálculos 1 e 2, para cursos de engenharia da UFPA, que visa lidar com os altos índices de retenção nas disciplinas de Cálculo. Dentro de sua estrutura, além de salas interligadas e interativas, espaços de estudo e encontros presenciais com monitores, o Projeto em questão utiliza a plataforma Moodle como sala de aula virtual para repositório de listas semanais e ambiente de interação entre estudantes, monitores e professores. Durante a ação piloto, no primeiro semestre de 2013, constatou-se uma permanência de $70 \%$ dos alunos até o final da disciplina de Cálculo 1 e $81 \%$ de aprovação dos estudantes que realizaram as três 
"Os desafios para formar hoje o engenheiro do amanhã"

avaliações (ABENGE, 2016). Destaca-se, ainda, que 92\% dos alunos ouvidos concordam que o Moodle colaborou para o desenvolvimento da disciplina.

\section{METODOLOGIA}

\subsection{Google Classroom no PCNA}

A utilização da plataforma Google Classroom no PCNA se deu da seguinte forma: cada turma teria uma sala de aula virtual para cada disciplina cursada (Física, Matemática, etc.) onde o monitor de cada uma seria responsável pela respectiva sala virtual. Estruturou-se cada sala em tópicos observando-se o padrão: bloco de assuntos (ex: Vetores, em Física; Aritmética, em Matemática; Tabela Periódica, em Química, etc.) contendo e-Book (teoria e exercícios propostos), slides, e videoaulas dos assuntos a serem abordados em sala; bloco de listas de exercício contendo as lista que abordavam o assunto ministrado a cada semana e bloco de testes.

Quanto ao acesso dos materiais na plataforma, estes foram disponibilizados da seguinte forma: eBooks - antes do início dos cursos de nivelamento, videoaulas - 48 horas antes da aula relacionada aquele assunto, slides - ao final do assunto, listas de exercício - aos domingos e testes - no dia pré-estabelecido e no horário combinado entre monitor e turma (com duração máxima de duas horas). Os envios das listas semanais e testes foram feitos pela plataforma, sendo que havia a possibilidade do discente entregar a resolução da lista presencialmente.

\subsection{Procedimento para obtenção dos dados}

Com o intuito de realizar o estudo objeto desta pesquisa, os autores determinaram como público alvo os cursistas do PCNA 2020, recém-ingressos, principalmente, nas 10 engenharias do ITEC e nos cursos do ICEN, com frequência acima de $70 \%$ nas aulas - sendo este o mínimo exigido para receberem certificado de carga horária. Assim, 203 alunos estavam aptos a participar da coleta de dados.

Tendo por base o método Survey interseccional, elaborou-se um questionário na plataforma Google Forms, no qual, em um intervalo de tempo definido, foram obtidos dados de interesse com base nas respostas fornecidas pelo espaço amostral definido (BABBIE, 1999). Os convites para participar do mesmo foram enviados por e-mail e aplicativo WhatsApp Messenger.

Inicialmente, solicitou-se dos participantes: nome completo e curso da graduação. As perguntas restantes se dividiram em 4 grupos de informações: (1) utilização e organização da plataforma, (2) estudo autônomo e prévio às aulas, (3) testes no formato virtual e (4) avaliação geral da plataforma.

Para a maioria das perguntas afirmativas, utilizou-se de uma escala de valores a fim de que os discentes expressassem sua concordância ou não com esta (LIKERT, 1932). A Tabela 1 correlaciona o nível de concordância/anuência com os valores da escala.

Tabela 1 - Correlação entre o nível de concordância e os valores associados.

\begin{tabular}{c|c}
\hline Nível de concordância & Valor na escala \\
\hline Concordo totalmente & 5 \\
\hline Concordo parcialmente & 4 \\
\hline Neutro & 3 \\
\hline Discordo parcialmente & 2 \\
\hline Discordo totalmente & 1 \\
\hline
\end{tabular}

Fonte: Autores 
"Os desafios para formar hoje o engenheiro do amanhã"

\subsection{Análise 1: Utilização e organização da plataforma}

A primeira análise consistiu em verificar: (1) se a utilização da plataforma fora de fácil usabilidade, (2) se os materiais didáticos (e-books, slides, vídeo aulas e listas de exercício semanais) estavam disponíveis de forma acessível e organizada e (3) o principal meio e localidade de acesso à plataforma. Neste último, disponibilizou-se uma lista de dispositivos (móveis e fixos) e locais (casa, trabalho e lan house) além de uma opção para o caso do discente não ter conseguido acesso.

\subsection{Análise 2: Estudo autônomo e prévio as aulas}

A segunda análise intencionava detectar: (1) caso o discente estudasse antecipadamente para as aulas, o quanto a disponibilidade prévia dos materiais didáticos na plataforma auxiliou no melhor entendimento das aulas presenciais e (2) se o uso do Google Classroom incentivou e auxiliou o seu estudo autônomo.

\subsection{Análise 3: Testes no formato virtual}

A terceira análise visou a impressão e o impacto da aplicação de testes avaliativos no formato virtual em relação aos presenciais. Questionou-se, também, a respeito das dificuldades encontradas na realização do(s) mesmo(s). Nesta, apresentou-se quatro obstáculos relatados pelos discentes durante as aulas: envio das respostas, conexão com a Internet, tempo de aplicação, visualização das questões, além de uma opção para o caso do discente não ter encontrado dificuldade.

\subsection{Análise 4: Avaliação geral da plataforma}

Neste critério, o discente foi questionado quanto à avaliação geral da plataforma Google Classroom como ferramenta educacional no curso de nivelamento do PCNA, além de oferecer um espaço para sugestões de melhorias do uso da mesma.

\section{RESULTADOS E DISCUSSÃO}

A partir dos dados coletados no questionário, envolvendo 120 participantes, pode-se visualizar o perfil do espaço amostral da pesquisa em questão. Este era majoritariamente constituído por jovens do sexo masculino com idades entre 16 e 19 anos. No que se refere aos cursos em que eram recém-ingressos, a maioria era dos cursos de Engenharia do Instituto de Tecnologia (75,83\%), dos quais destacaram-se as Engenharias Civil (18,68\%), Química (14,28\%) e Sanitária e Ambiental (12,09\%).

\subsection{Análise 1: Utilização e organização da plataforma}

A estruturação com a qual os materiais didáticos e recursos complementares para ensinoaprendizagem fora organizada visava que estes estivessem de forma mais acessível aos alunos que participariam do curso de nivelamento. A Tabela 2 apresenta o nível de concordância dos cursistas PCNA quando questionados sobre a facilidade de utilização das funcionalidades da plataforma (local para tirar dúvidas, entrega das atividades, etc.).

Tabela 2 - Nível de concordância com a usabilidade da plataforma pelo discente.

\begin{tabular}{c|c}
\hline Nível de concordância & Percentual $(\%)$ \\
\hline Concordo totalmente & 70,00 \\
\hline Concordo parcialmente & 25,00 \\
\hline Neutro & 1,67 \\
\hline Discordo parcialmente & 3,33 \\
\hline
\end{tabular}


C COBENGE

"Os desafios para formar hoje o engenheiro do amanhã"

\begin{tabular}{l|c}
\hline Discordo totalmente & 0,00 \\
\hline Fonte: Autores
\end{tabular}

Pode-se concluir, a partir da Tabela 2, que uma grande parcela (95\%) assentia positivamente com a usabilidade da plataforma.

Quando questionados especificamente a respeito da sequência didática dos materiais didáticos, percebeu-se, a partir da Tabela 3, que, novamente, a maioria absoluta dos participantes $(96,87 \%)$ concordava.

\begin{tabular}{|c|c|}
\hline Nível de concordância & Percentual $(\%)$ \\
\hline Concordo totalmente & 79,17 \\
\hline Concordo parcialmente & 17,50 \\
\hline Neutro & 2,50 \\
\hline Discordo parcialmente & 0,83 \\
\hline Discordo totalmente & 0,00 \\
\hline
\end{tabular}

Fonte: Autores

Na sequência, a fim de descobrir o principal meio de acesso à plataforma, notou-se, de acordo com a Tabela 4, que o acesso majoritário dos estudantes $(67,5 \%)$ fora feito de dispositivos móveis, das residências dos mesmos.

Tabela 4 - Principal meio de acesso à plataforma.

\begin{tabular}{c|c}
\hline Meio de acesso & Percentual $(\%)$ \\
\hline Dispositivo móvel em casa & 67,50 \\
\hline Computador em casa & 28,33 \\
\hline Dispositivo móvel na Universidade & 1,67 \\
\hline Não possuí meio de acesso & 1,67 \\
\hline Computador no trabalho & 0,83 \\
\hline
\end{tabular}

Fonte: Autores

Os dados, em relação ao dispositivo de acesso, já eram esperados devido à comodidade que o aplicativo da plataforma oferece e nem todos possuírem computador em sua casa. Quanto ao local em que era realizado o acesso, também já era esperado devido às limitações de redes Wi-fi e de dados ofertadas na universidade. Finalmente, é válido ressaltar que o objetivo principal dos três questionamentos anteriores serem feitos ao aluno era verificar a acessibilidade da plataforma ao público alvo.

\subsection{Análise 2: Estudo autônomo e prévio as aulas}

No que diz respeito à importância do estudo antecipado às aulas com os materiais disponibilizados no Google Classroom, nota-se, a partir da Tabela 5, que mais de 54\% dos discentes concordaram com esta afirmação.

Tabela 5 - Nível de concordância com a importância do estudo prévio para o entendimento das aulas presenciais.

\begin{tabular}{c|c}
\hline Nível de concordância & Percentual $(\%)$ \\
\hline Concordo totalmente & 19,17 \\
\hline Concordo parcialmente & 35,00 \\
\hline Neutro & 23,33 \\
\hline
\end{tabular}


"Os desafios para formar hoje o engenheiro do amanhã"

\begin{tabular}{l|l}
\hline Discordo parcialmente & 10,83 \\
\hline Discordo totalmente & 11,67 \\
\hline Fonte: Autores
\end{tabular}

Dos dados da Tabela 5, constatou-se que 93,75\% afirmaram concordância (parcial ou total) com o fato de ter acesso aos materiais didáticos de maneira prévia teve um impacto positivo no entendimento quando o conteúdo foi abordado em classe. Destaca-se, ainda, que mais de 78\% assinalaram "concordo totalmente" com a afirmação anterior.

A constatação desse resultado foi de suma importância, pois a proposta de transição do modelo educacional tradicional para o ensino híbrido exigia que o aluno compreendesse a relevância do seu papel na busca pelo conhecimento, lendo previamente os materiais disponibilizados na plataforma.

Entretanto, em comparação com os demais itens questionados no formulário, "importância do estudo prévio para o entendimento das aulas presenciais" foi o único em que os níveis de discordância (total ou parcial) são significativos. De certo modo, isto era esperado devido à apresentação da metodologia - que é bem distante das metodologias utilizadas no ensino médio - não ter sido tão eficaz quanto o desejado por parte da coordenação do curso de nivelamento o que ocasionou um entendimento tardio do método de ensino por parte do aluno. Essa percepção se deu por meio dos comentários dos alunos ao final do questionário.

Quando questionados sobre o impacto do Google Classroom na sua autonomia em relação aos estudos, mais de $92 \%$ dos alunos indicaram nível de concordância positivo (concordância total ou parcial). Os dados são apresentados na Tabela 6.

Tabela 6 - Nível de concordância com a influência do Google Classroom no estudo autônomo.

\begin{tabular}{c|c}
\hline Nível de concordância & Percentual (\%) \\
\hline Concordo totalmente & 67,50 \\
\hline Concordo parcialmente & 25,00 \\
\hline Neutro & 5,00 \\
\hline Discordo parcialmente & 2,50 \\
\hline Discordo totalmente & 0,00 \\
\hline
\end{tabular}

Fonte: Autores

Apesar de os dados da Tabela 5 se apresentarem aquém do desejável, os apresentados na Tabela 6 reforça que, para os discentes que estudavam de maneira prévia as aulas por meio dos recursos oferecidos na plataforma, a influência foi positiva para desenvolvimento do hábito de estudar de forma autônoma.

\subsection{Análise 3: Testes no formato virtual}

Outro ponto de estudo foram os testes de avaliação do aprendizado, realizados virtualmente na plataforma. Neste item, conforme se pode observar na Tabela 7 , mais de $76 \%$ dos discentes indicaram avaliação positiva de que os testes virtuais, igualmente aos presenciais, permitiram ao discente realizar uma autoavaliação do aprendizado.

Tabela 7 - Nível de concordância com autoavaliação positiva do aprendizado em testes no formato virtual.

\begin{tabular}{c|c}
\hline Nível de concordância & Percentual (\%) \\
\hline Concordo totalmente & 49,17 \\
\hline Concordo parcialmente & 27,50 \\
\hline
\end{tabular}


"Os desafios para formar hoje o engenheiro do amanhã"

\begin{tabular}{c|c}
\hline Neutro & 11,67 \\
\hline Discordo parcialmente & 7,50 \\
\hline Discordo totalmente & 4,17 \\
\hline Fonte: Autores
\end{tabular}

O embasamento para tal questionamento se deve ao fato de que, nos testes presenciais, a supervisão dos monitores inibia o acesso a recursos não permitidos. No formato virtual, era colocado aos discentes que o uso de meios ilícitos só os prejudicariam. Acredita-se que as motivações dos que discordaram com a afirmativa proposta foram às mencionadas anteriormente.

Em seguida, verificaram-se as principais dificuldades encontradas pelos alunos na realização dos testes no formato virtual. Os dados são apresentados no Gráfico 1.

Gráfico 1 - Adversidades encontradas pelos discentes durante a realização dos testes virtuais.

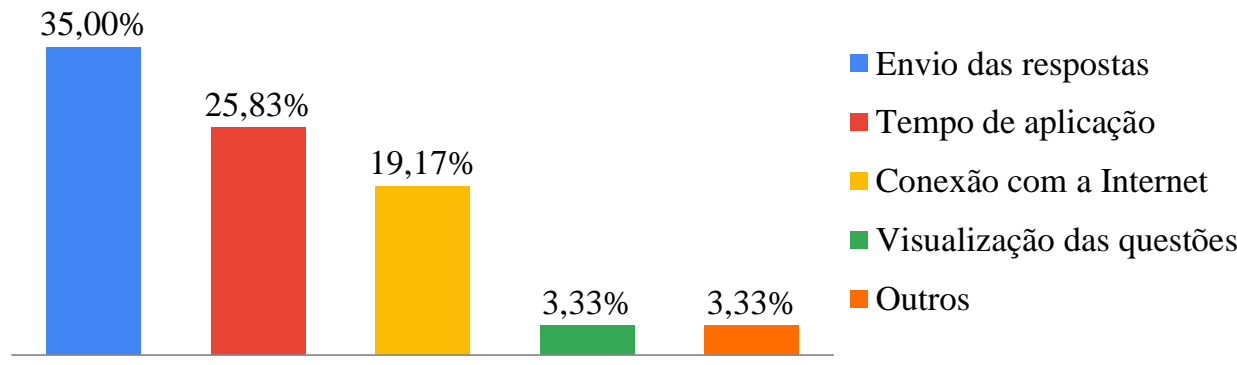

Fonte: Autores (2020)

Observou-se, a partir do Gráfico 1, que as três principais dificuldades foram: o envio das respostas pela plataforma (35\%), tempo de aplicação $(25,83 \%)$ e conexão com a Internet $(19,17 \%)$. Os problemas para envio das respostas e conexão com a internet fugiam ao controle dos monitores que ficavam de plantão remoto com a turma enquanto o teste era aplicado.

Para contornar a primeira adversidade, foi permitido que alunos envolvidos enviassem registos das resoluções por imagem, via aplicativo WhatsApp Messenger. Quanto ao tempo de aplicação, este fora de 20 minutos a 1 hora maior do que quando realizado presencialmente, em edições anteriores. Porém, levou-se em consideração o tempo gasto para criar um registro fotográfico da resolução e enviar pela plataforma. Os monitores possuíam liberdade para acrescentar tempo extra. Aos alunos que assinalaram "Conexão com a Internet", foram disponibilizadas opções para realização dos testes no contraturno do PCNA.

Como não foi imposto limite às opções com os problemas encontrados, foi possível analisar-se a existência de algum vínculo entre as opções marcadas. Observou-se que os que assinalaram "Conexão com a Internet", 34,78\% também assinalaram "Envio das respostas". Esse vínculo entre as duas era esperado pela própria necessidade de ter uma mínima conexão de Internet para enviar as questões. Enfim, dos que assinalaram "Tempo de aplicação", 22,58\% também escolheram a opção "Envio das respostas". Esta também era esperada em virtude dos discentes demandarem grande parte do tempo de aplicação do teste para resolução das perguntas e não reservarem tempo para o envio das respostas.

\subsection{Análise 4: Avaliação geral da plataforma}

Finalizando as análises, a Tabela 8, a seguir, apresenta o nível de concordância com a avaliação geral positiva da utilização da plataforma Google Classroom no PCNA. 
"Os desafios para formar hoje o engenheiro do amanhã"

Tabela 8 - Nível de concordância com a avaliação positiva da utilização do Google Classroom no PCNA.

\begin{tabular}{c|c}
\hline Nível de concordância & Percentual (\%) \\
\hline Concordo totalmente & 75,83 \\
\hline Concordo parcialmente & 20,83 \\
\hline Neutro & 1,67 \\
\hline Discordo parcialmente & 1,67 \\
\hline Discordo totalmente & 0,00 \\
\hline Fonte: Autores
\end{tabular}

Na Tabela 8, verifica-se que, aproximadamente, 97\% dos participantes concordaram com essa avaliação, além de que 3/4 do total assinalaram plena concordância. De semelhante forma, na maioria dos dados apresentados anteriormente, os índices de discordância se mantiveram muito baixos. No caso deste último questionamento, 1,67\% dos discentes que discordam da avaliação positiva do Google Classroom no PCNA indica uma possível resistência a modelos inovadores de ensino. Outra possibilidade, de certa forma compreensível, seria que este percentual representa os discentes que tiveram algum problema (envio dos testes, download dos materiais, etc.) com a plataforma no decorrer do curso.

Por fim, ao analisar as opiniões dos alunos no espaço aberto para sugestões de melhorias e mudanças a serem feitas no uso da plataforma, verificou-se que estes utilizaram, em sua grande maioria, para destacar as dificuldades enfrentadas (analisadas no item 4.3), expressão de satisfação e concordância com a utilização da plataforma, com proposição de uso mais intensivo dos recursos dessa ferramenta educacional. Esse feedback foi extremamente positivo e reforça a necessidade de utilização das tecnologias disponíveis para possibilitar melhorias no processo de ensino-aprendizagem nas instituições de ensino.

\section{CONSIDERAÇÕES FINAIS}

O estudo teve como objetivo levantar a aceitação e possíveis dificuldades de uma metodologia de ensino híbrido aplicada em um curso de nivelamento de uma Instituição Federal de Ensino Superior. Por meio de um questionário foi feito um mapeamento dos principais pontos positivos da utilização do Google Classroom como ferramenta de apoio na proposta de ensino Híbrido do PCNA e das principais dificuldades encontradas pelos alunos.

Os dados da pesquisa mostraram que a configuração "ensino presencial + ferramentas e recursos do Google Classroom" se demonstrou benéfica e aplicável. Permitiu ao aluno desenvolver seu estudo autônomo, no seu tempo disponível em local acessível, proporcionando-lhe melhor condicionamento em pré-requisitos de conteúdo iniciais da graduação, permitindo aos discentes melhor desenvolvimento no decorrer do curso.

Para uma visualização mais ampla deste modelo de ensino, sugere-se uma análise envolvendo evasão e nível de conhecimento prévio e posterior ao nivelamento comparando estes com uma edição anterior ao uso do ensino híbrido.

\section{REFERÊNCIAS}

BABBIE, Earl. Métodos de Pesquisas de Survey. Tradução Guilherme Cezarino. Belo Horizonte: Ed. UFMG, 1999, p. 519.

BARDAGI, Marucia; HUTZ, Claudio Simon. Evasão universitária e serviços de apoio ao estudante: uma breve revisão da literatura brasileira. Psicologia Revista, [S.1.], v. 14, n. 2, p. 279-301, fev. 2014. ISSN 2594-3871. 
"Os desafios para formar hoje o engenheiro do amanhã"

CHRISTENSEN, C.; HORN, M.; STAKER, H. Ensino Híbrido: uma Inovação Disruptiva? Uma introdução à teoria dos híbridos. Clayton Christensen, 2013. Disponível em: https://www.christenseninstitute.org/publications/ensino-hibrido/. Acesso em: 15 maio 2020.

PARISOTO, et al., Ressignificação do ensino para a formação de novos engenheiros: das estratégias ativas de aprendizagem ao mundo contemporâneo. In: DESAFIOS DA EDUCAÇÃO EM ENGENHARIA: Processos de Ingresso, Perfil do Professor, Aprendizagem Multidisciplinar, Inovação e Proposições /Vanderlí Fava de Oliveira, Octavio Mattasoglio Neto e Marcos José Tozzi - Organizadores - Brasília: ABENGE, 2016

LIKERT, R. A technique for the measurement of attitudes. Archives in Psychology, 140, p. $1-55,1932$

SEMESP. Mapa do Ensino Superior no Brasil: 2017. São Paulo, 2019. 244 p.

MORAN, José. Desafios que as tecnologias digitais nos trazem. In: MORAN, M. Novas tecnologias e mediação pedagógica. Campinas, São Paulo: Papirus, 2013.

MORAN, José. Educação híbrida: um conceito-chave para a educação, hoje. In: BACICH, Lillian.; NETO, Adolfo Tanzi; DE MELLO TREVISANI, Fernando. Ensino híbrido: personalização e tecnologia na educação. Porto Alegre: Penso, p. 27-45, 2015.

MOREIRA, Marco Antônio. Aprendizagem significativa crítica. In: III Encontro Internacional sobre Aprendizagem Significativa, 2000, Peniche. Anais, p. 47, 2000.

WITT, D. Accelerate learning with Google apps for education. 2015. Disponível em: https://danwittwcdsbca.wordpress.com/2015/08/16/accelerate-learning-with-google-apps-foreducation/. Acesso em: 25 de maio de 2020.

\title{
GOOGLE CLASSROOM AS AN EDUCATIONAL TOOL IN THE HYBRID TEACHING PROPOSAL OF PCNA
}

\begin{abstract}
It is notable the deficiency of knowledge presented by public schools derived students entering engineering courses. A consequence of such problem is reflected in the retention and failure rates, since this deficiency does not allow the student to follow the course and complete it within the minimum time. In attempt to minimize these consequences, initiatives and strategies such as the Learning Leveling Course Program (PCNA) of the Federal University of Pará (UFPA), a proposal aimed at reducing failure rates in engineering courses through the offering of leveling courses, are extremely important. Using a quantitative approach based on the intersectional Survey method, this article seeks to analyze the impact and effectiveness of using the Google Classroom platform as an educational tool for students in a presential leveling course supported by virtual teaching and learning resources. Adherence to the proposed methodology, accessibility, availability of the offered resources and encouragement of autonomous study showed positive results after the course completion. Hence, it is expected encouraging the use of such teaching and learning technological tools by educational institutions, especially in the current context, in which remote education has become necessary.
\end{abstract}

Keywords: Hybrid Teaching. Flipped Classroom. Google Classroom. PCNA. 